\title{
La ideología anarquista de Manuel González Prada en la prensa libertaria peruana de comienzos de siglo XX
}

\author{
The anarchist ideology of Manuel González Prada in the libertarian Peruvian press of the \\ beginning of the $\mathrm{XX}^{\text {th }}$ century
}

Ivanna Margarucci*

Resumen: En el presente artículo nos proponemos indagar sobre algunos aspectos de la ideología anarquista de Manuel González Prada, analizando sus artículos en prosa, publicados en la prensa libertaria peruana de la primera década del siglo XX. En el centenario de su muerte, es importante poder responder dos preguntas, que son en verdad una. ¿Qué tenía González Prada para decirle a los trabajadores que leían o a los que les llegaba de otras maneras esa prensa? ¿Qué ideas recibieron de él en esta etapa formativa del anarquismo peruano?

Palabras clave: Anarquismo, Manuel González Prada, Perú, Prensa libertaria, Historia intelectual

\begin{abstract}
In this article we aim to address about some aspects of the anarchist ideology of Manuel Gonzalez Prada, analyzing its articles in prose, published in the libertarian Peruvian press of the first decade of the XX ${ }^{\text {th }}$ century. In the centenary of his death, it is important to be able to answer two questions, which in fact are only just one. What did González Prada have to say to the workers that read or received in other ways that type of press? Which ideas happened to receive from him at this formative stage of the Peruvian anarchism?
\end{abstract}

Key words: Anarchism; Manuel González Prada; Perú; Libertarian press; Intelectual history

Recibido: 9 octubre 2018 Aceptado: 19 diciembre 2018

\section{Introducción}

A pesar de la vasta producción existente sobre el movimiento libertario peruano, algunos tópicos de esta rica experiencia han sido relegados o escasamente trabajados. En general, la atención de esta historiografía se centra sobre tres grandes ejes, aquellas que fueron sus principales actividades: la labor editorial, el activismo sindical y el proyecto cultural. Pero relega, por ejemplo, la importante presencia de algunos intelectuales radicales y anarquistas y el papel que cumplieron en la difusión y surgimiento del anarquismo local en el tránsito del siglo XIX al XX: Manuel González Prada, Christian Dam y Gliserio Tassara, por mencionar a las figuras más destacadas. Es decir, no se ha estudiado en profundidad, en clave de historia 
intelectual, el aporte conceptual que estos realizaron -pensamiento que lógicamente construyeron de forma dialogada, entre ellos y con su época. Dicha historiografía sí ha insistido en el rol relevante que tuvo González Prada en ese proceso $^{1}$; sin embargo, pocos han sido los autores que se dedicaron a estudiar cuál fue su aporte en concreto.

Entre esos estudiosos, podemos mencionar al peruano Luis Alberto Sánchez, quien desde muy temprano se abocó a reconstruir la vida y obra de González Prada ${ }^{2}$ en dos importantes libros, publicando más tarde otras obras igualmente relevantes. ${ }^{3}$ En la actualidad, el francés Joel Delhom ${ }^{4}$ y el norteamericano Thomas Ward ${ }^{5}$, dieron continuidad a esa labor. En conjunto, estos trabajos han echado luz sobre algunos aspectos centrales del pensamiento ético-filosófico, político y social de Prada -no sólo sobre el período anarquista, sino en relación a todas las estaciones ideológicas que transitó-, revelando de modo más general, la densidad de este pensador difícilmente clasificable en términos literarios y políticos.

En el centenario de la muerte de Manuel González Prada, resulta fundamental continuar profundizando en ese universo intelectual tan vasto y complejo, rescatar su profusa, aunque fragmentada producción de tinte libertaria y recuperar de ella la unidad de su pensamiento, para comprender de qué se trató efectivamente y cuál fue la importancia de la contribución realizada por este intelectual procedente de la élite limeña, en la formación ideológica de los trabajadores peruanos.

Para ello, nos concentraremos en el análisis de sus artículos en prosa, publicados en su mayoría entre 1904 y 1909 en el mensual anarquista Los Parias de Lima, ponderando la definición de Anarquía provista por el autor y sus ideas acerca de la tríada explotadora y opresora, compuesta por el Estado, la Iglesia y el Capital -que constituyó el enemigo principal de la ideología anarquista, desde su propia constitución en la Europa de la segunda mitad del SXIX. Antes, repasaremos la trayectoria de González Prada e indagaremos acerca de las razones que lo llevaron en una etapa tardía de su vida, a identificarse con el anarquismo.

\section{El sinuoso recorrido de González Prada}

Mucho se ha escrito sobre la trayectoria intelectual de Manuel González Prada. Distintas fueron, y siguen siendo, las preocupaciones y los enfoques de los autores de esta extensa bibliografía. Sin embargo, hay entre ellos consensos comunes, lugares casi ineludibles. Primero, destacar el compromiso de Prada con la realidad política y social que le tocó vivir, que hizo de él una figura central, precursora en la historia del pensamiento crítico peruano. Segundo, señalar la transformación de su producción literaria y la variación de su identificación política, distinguiendo más o menos sistemáticamente cuatro períodos o momentos en la "evolución del pensamiento y la acción" del intelectual. ${ }^{6}$

\footnotetext{
* Argentina. Profesora de Enseñanza Media y Superior en Historia (UBA). Becaria doctoral del CONICET con lugar de trabajo en CeDInCI/UNSAM. Estudiante del Programa de Doctorado en Historia (UBA). Dirección de correo electrónico: ivannamargarucci@gmail.com

1 Véase: Hugo García Salvattecci, El pensamiento de González Prada, Lima, Editorial Arica, 1972, p. 17 y Denis Sulmont, Historia del movimiento obrero peruano (1890-1977), Lima, Centro de Publicaciones Educativas, 1977, p. 19.

${ }^{2}$ Luis Alberto Sánchez, Elogio de Don Manuel González Prada, Lima, Imp. Torres Aguirre, 1922 y Luis Alberto Sánchez, Don Manuel, Lima, Editorial Rosay, 1930.

${ }^{3}$ Luis Alberto Sánchez, Mito y realidad de González Prada, Lima, Ed. Villanueva, 1976 y Luis Alberto Sánchez, Nuestras vidas son los ríos... Historia y leyenda de los González. Prada, Lima, Universidad Nacional Mayor de San Marcos, Dirección Universitaria de Biblioteca y Publicaciones, 1977.

4 Joel Delhom, Manuel González Prada et ses sources d'influence. De la philosophie à la politique, Thèse de doctorat en Études ibériques, Université de Perpignan, janvier 1996.

5 Thomas Ward, La anarquía inmanentista de Manuel González Prada, Lima, Universidad Ricardo Palma; Editorial Horizonte, 2001 y Thomas Ward (ed.), "El porvenir nos debe una victoria": la insólita modernidad de Manuel González Prada, Lima, Red para el Desarrollo de las Ciencias Sociales en el Perú, 2010.

${ }^{6}$ Manuel Sobrevilla, "Intelectuales en el Perú: literatura, sociedad y política", en Patio de Letras, Vol. II, 2004, n¹, pp. 33-44.
} 
El primero de ellos remite a los años de "formación". Nacido en Lima el 5 de enero de 1844 en el seno de una familia católica y conservadora de la oligarquía limeña, González Prada estudió durante un breve lapso en el Colegio de San Carlos y luego continuó haciéndolo de forma autodidacta. En este período, se desarrolló y afirmó como escritor, realizando traducciones y escribiendo piezas de distinto género (prosa, obras teatrales, poesías, letrillas y baladas). En poco tiempo, pese a no haber publicado ningún libro, se convirtió en un poeta reconocido. Ayudaron a ello, su admisión en la Sección de Artes y Letras del Club Literario y sus colaboraciones regulares en el periódico El Correo del Perú. Surge aquí, en este momento, el anticlericalismo que lo caracterizará durante toda su vida, a la vez que se acerca, tímidamente, al pensamiento liberal. Entre 1871 y 1879 Prada se radicó en la hacienda familiar Tútume, ubicada en el Valle de Mala, al sur de Lima. Allí, se dedicó a actividades agrícolas. Siguió leyendo y traduciendo. También "el hombre de ciudad, se encontró, de cerca, con los indígenas. Un contacto que fue físico e intelectual, pues descubrió al Inca Garcilaso, una influencia literaria directa en las Baladas Peruanas (1935) que habrá de componer en la hacienda", siendo esta la primera de sus múltiples reflexiones acerca de la problemática cuestión del indio. ${ }^{7}$

El segundo período del escritor, el "radical-positivista"8, comienza en 1879 con un hecho trascendental: la Guerra del Pacífico, librada entre Chile, Bolivia y Perú (1879-1883). El capitán de compañía González Prada, luego teniente coronel y segundo jefe del batallón N50 de la novena compañía, participó en las batallas de San Juan y Miraflores en enero de 1881. Al producirse la toma de Lima por los chilenos, se encerró en su casa hasta la firma del Tratado de Ancón en 1883. Tras el resultado adverso del conflicto bélico, que determinó la ocupación de las provincias peruanas de Tacna y Arica, en lo sucesivo, Prada no podrá escindir su producción intelectual de la actividad política. Esta nueva orientación se manifestó, por ejemplo, en el abandono del Club Literario, núcleo de los literatos consagrados y conservadores, y la fundación en 1886 junto a otros jóvenes escritores del Círculo Literario, asociado al pensamiento radical y anticlerical, del que llegará a ser primero vicepresidente y luego presidente.

1888 fue un año muy importante en su vida: "pronunció entonces sus famosos discursos en el teatro Politeama (...) y en el teatro Olimpo (...), y escribió el artículo 'Propaganda y ataque' (...) Estos textos lo convirtieron de un líder literario en un líder político". ${ }^{9}$ En el primero de ellos, González Prada cuestiona el curso de la historia peruana, desde la colonia hasta el período independiente. La república carece de una nación; su sociedad atraviesa una profunda crisis moral y terminal. ${ }^{10}$ La metáfora organicista que encuentra para caracterizarla en el último escrito, es la de un "organismo enfermo: donde se aplica el dedo brota pus". ${ }^{11}$ La guerra, Tacna y Arica, se habían perdido por ese motivo.

El futuro era entonces de las nuevas generaciones, los "árboles nuevos (...) ¡Los viejos a la tumba, los jóvenes a la obra!". ${ }^{2}$ La obra "de propaganda i ataque" de los escritores, cómo él, era clave para "regenerar" política y económicamente el cuerpo enfermo. "Tal vez no vivimos en condiciones de intentar l'acción colectiva, sino el esfuerzo individual i solitario" advertía. Tenía sí, que ser honrada, verdadera en el estilo y las ideas, y esencialmente comprometida a partir de un objetivo doble. Destruir por arriba, "inferirse en la política para desacreditarla, disolverla i destruirla" e instruir por abajo, dar "continuas descargas eléctricas al organismo amenazado de parálisis (...) herir i punzar a las multitudes (...) por el jeneroso deseo de

\footnotetext{
7 Ivanna Margarucci, "Manuel González Prada. Preguntas, respuestas y propuestas sobre la cuestión indígena durante un cuarto de siglo del Perú contemporáneo, 1871-1906", en Revue Amerika - Dossier "En torno a Manuel González Prada: el pensamiento radical como fermento literario y social", $\mathrm{n}^{\circ} 17$, Université Rennes 2, Haute Bretagne, 2018. Disponible en línea $<$ https://journals.openedition.org/amerika/8377> (11/10/2018).

8 González Prada se identifica en esta etapa con el positivismo. Cree, deposita sus esperanzas en la evolución al "estado positivo" y en la centralidad de la ciencia, pero a diferencia del de Comte, no lo asume como un ideario conservador. Pues evolución equivale para aquel, a transformación radical de la sociedad -y más adelante, como se verá, a revolución.

${ }^{9}$ Sobrevilla, op. cit., p. 34.

10 Manuel González Prada, "Discurso en el Politeama" (1888), en Manuel Sobrevilla (comp.), Manuel González. Prada. jLos jóvenes a la obra! Textos esenciales, Lima, Fondo Editorial del Congreso del Perú, 2009, pp. 237-239.

11 González Prada, "Propaganda i ataque" (1888) en Sobrevilla, Ibid., p. 257.

12 González Prada, "Discurso en el Politeama", en Sobrevilla, Ibid., p. 240.
} 
estimularlas para el bien i enardecer el coraje para l'acción"..13 Una concepción del rol del intelectual distinta a la que propondrá algunos años después.

El análisis de los problemas de Perú y las propuestas políticas de Prada, esbozadas en esos y otros textos -compilados en Pájinas Libres (1894)- se condensaron en el radical programa de la Unión Nacional, partido político que él y su entorno del Círculo Literario fundaron en 1891. Poco tiempo después partió con su esposa hacia Europa, sellándose el alejamiento temporal del proyecto.

Los "años europeos", el tercer período en la biografía del autor, transcurren entre 1891 y 1898, en tres ciudades del viejo continente: París, Barcelona y Madrid. El trayecto que recorre, los libros que lee, las conferencias a las que atiende, las personas a las que conoce, serán decisivas para el viraje ideológico que se produce en la que podríamos caracterizar como una "etapa bisagra", entre el "radical-positivismo" característico de la anterior -que todavía cultiva y que, en algunos aspectos, no abandonará nunca- y el "radical-anarquismo" -con el que entra en contacto y se identificará hasta su muerte. Ambas vertientes ideológicas lo nutren durante su estancia europea. A Prada lo fascinaba la figura de Ernst Renan, a quien escucha disertar dos veces a la semana en París, pero también capturaron su atención los escritos de Joseph Pierre Proudhon, Mijail Bakunin y Piotr Kropotkin, "padres" de un anarquismo que emergía de la propia realidad con la que se topó el peruano: de las cenizas de la Comuna de París y de la futura experiencia libertaria que, con la organización de trabajadores y campesinos, comenzaba a gestarse en aquella que en un artículo posterior llamó, la "nueva España". ${ }^{14}$

La vuelta de González Prada a su país, da inicio al cuarto y último período, el "radical-anarquista". Los hombres de la Unión Nacional, más preocupados en establecer alianzas con el Partido Liberal o mismo en concretar sus ambiciones políticas, no acompañaron a Prada en su reconversión ideológica, más bien lo dejaron solo. Fue así como, tras el intento fallido de reorientar dicho partido en una dirección más radical, en 1902 rompió sus vínculos con él y comenzó a tender nuevos lazos con el mundo de los trabajadores y artesanos libertarios.

En marzo de 1904 comenzó a publicarse el periódico anarquista Los Parias. Por la redención social de Lima, primer periódico anarquista del Perú. Según Jesús Ballivian, se trató del "proyecto más ambicioso" de González Prada. A pesar que su amigo, el joyero Pedro Pablo Astete era su director formal, servía en verdad como mero administrador, siendo Prada la "verdadera fuerza intelectual" detrás de la publicación, en lo que respecta a su estructura y también contenido, dada la gran cantidad trabajos con los que colaboró. ${ }^{15}$

En esa misma senda, los panaderos encabezaron diversas actividades para conmemorar en 1905 el primer $1^{\circ}$ de mayo en Perú, lo que incluyó una velada en donde González Prada leyó la ponencia "El intelectual y el obrero" ante la gran audiencia trabajadora que colmó el Teatro Politeama. Allí, el autor señalará que no hay división ni "diferencia de jerarquía entre el pensador que labora con la inteligencia y el obrero que trabaja con las manos". Iguales en importancia, trabajo intelectual y manual se complementan y retroalimentan. A diferencia de lo planteado en "Propaganda i ataque", las revoluciones son presentadas como acciones colectivas: "vienen desde arriba" dice -justificando su propia forma de intervención- y "se operan desde abajo", porque la acción de las masas -a las que él quiere llegar, justamente, a través de Los Parias- desborda esa actuación, neutralizando la pretendida superioridad de los intelectuales. ${ }^{16}$

De esta etapa, datan tres importantes libros, que reúnen parte de su vasta producción literaria: Horas de Lucha (1908), Presbiterianas (1909) y Exóticas (1911). El primero de ellos se destaca por su contenido político: en sus artículos, todos ellos del último período, denuncia los males de la sociedad y política peruana y esboza posibles soluciones para acabar con ellos y transformar a aquella de raíz.

\footnotetext{
13 González Prada, "Propaganda i ataque" (1888) en Sobrevilla, Ibid., pp. 257-261.

14 Manuel González Prada, "Cosas de España" (1905), en Prosa menuda, Buenos Aires, Edit. Imán, 1941, p. 237.

15 Jesus Ballivian, Anarchism and the press in Lima. The case of Los Parias, Thesis submitted for the degree of Master of Arts in Latin American Studies, University of Illinois, 2010, pp. 27-28.

16 Manuel González Prada, "El intelectual y el obrero" (1905), en Anarquía, Santiago de Chile, Edit. Ercilla, 1940 , pp. 68 y 71.
} 
Su vinculación con las clases populares y el anarquismo, no fue en desmedro del continuo reconocimiento que recibió de parte de algunos sectores ilustrados de la élite del Perú, debido a sus dotes como escritor y la reputación que había conquistado. Así, en 1912 el autor fue nombrado Director de la Biblioteca Nacional, renunciando al cargo en febrero de 1914 a causa del golpe de Estado encabezado por el coronel Óscar R. Benavides. Prada se pronunció en una serie de artículos contra su dictadura y, más generalmente, contra el "caporalismo", la "tiranía de los militares", compilados luego por su hijo Alfredo González Prada en Bajo el Oprobio (La dictadura militar de 1914-15) (1933). La asunción de un nuevo gobierno constitucional en 1915, lo devolvió a la dirección de la biblioteca algunos meses después, para continuar al frente de ella hasta su muerte, cuando su corazón se detuvo, un 22 de julio de 1918.17

\section{Los dos siglos de González Prada}

¿Por qué González Prada, rondando los sesenta años de edad, decidió hacerse anarquista? Dos son las razones que convergen en esta etapa tardía de su vida y explican, a grosso modo, tal evolución ideológica. ${ }^{18}$

En primer lugar, es necesario considerar el problema en una dimensión teórico-filosófica, relacionada con las ideas que fue cultivando sobre algunos aspectos morales y éticos, inescindibles de su pensamiento social.

Como señalamos, el positivismo y evolucionismo de Prada, lejos estuvo del conservadurismo decimonónico, lo cual le permitió aproximarse a una concepción de evolución que no tendía al mejoramiento de la raza a través de la lucha por la existencia y la selección natural, sino a la emancipación de la humanidad. González Prada, dice él mismo: "si el darwinismo mal interpretado parecía justificar la dominación de los fuertes y el imperialismo despótico, bien comprendido llega a conclusiones humanitarias". ${ }^{19}$ ¿Cómo? La clave de esta lectura alternativa parte también de la naturaleza, en tanto fuente primordial de los valores morales, permitiendo la voluntad de la especie humana una progresiva elevación de la moral, entendida como sinónimo de liberación. La moral no es inmutable, ni "se alberga en biblias ni códigos, sino en nosotros mismos", revelándose como una práctica necesaria y cotidiana, y por lo tanto, variable y relativa. ${ }^{20}$ ¿Cuáles son los valores que del hombre destaca Prada? Ideales llamativamente muy cercanos, desde lo discursivo, a los que exalta el catolicismo: el amor al prójimo ${ }^{21}$; la conmiseración y la justicia ${ }^{22}$; la resignación y el sacrificio. ${ }^{23}$ Pero que se alejan de la religión, pues mientras para esta son sinónimo de sumisión, para el pensador lo son de rebeldía. González Prada produce así ese desliz de sentido que Joel Delhom conceptualiza como "trasposición atea", una operación semiótica que permitiría "elaborar un discurso de regeneración social laica" a partir del uso -la manipulación- de los códigos simbólicos y morales del adversario ideológico. ${ }^{24}$

Del mismo modo, la ética no es teoría sino, fundamentalmente, acción individual que deviene social: su esencia es el "altruismo" (antítesis del egoísmo) y el "auxilio mutuo" (o "protección recíproca") -conceptos mencionados, explicados y hasta personificados reiteradamente en su obra. A partir de ellos,

\footnotetext{
17 Para la biografía de Manuel González Prada, véase además de la bibliografía citada, aquella mencionada en la introducción. 18 No exclusiva ni original de él; pensemos, por ejemplo, en el camino recorrido por Ricardo Flores Magón en México, también, del liberalismo al anarquismo. Véase: Juan Gómez Quiñones, Las ideas políticas de Ricardo Flores Magón néxico DF, Ediciones Era, 1977.

19 González Prada, "La Anarquía" (1907), en Anarquía, op. cit., p. 18.

20 González Prada, "El individuo" (c. 1910-1918), en Ibid., pp. 157-158.

21 González Prada, "Luisa Michel" (c. 1904-1909), en Ibid., p. 141.

22 González Prada, "La acción individual" (c. 1910-1918), en Ibid., p. 124.

23 González Prada, "El intelectual y el obrero", en Ibid., p. 75.

${ }^{24}$ Joel Delhom, "Esbozo de una tipología temática y funcional de los usos de la biblia en el anarquismo hispánico", Joel Delhom y Daniel Attala (dirs.), Cuando los anarquistas citaban la Biblia. Entre mesianismo y propaganda, Madrid, Catarata, 2014, p. 267.
} 
la lucha individual se transforma en lucha de clases y el pasaje de la "barbarie" a la "civilización" resulta un progreso tanto "moral" como "social".

La conclusión a la que Prada llega a través de este razonamiento -inducido por pensadores anarquistas como Kropotkin y Eliseo Reclús- será su puerta de entrada a esta ideología, a la que define como científica y a la vez, una "doctrina de amor y piedad, esa exquisita sublimación de las ideas humanitarias". 25

En segunda instancia, en una dimensión más "práctica y concreta", pero relacionada con la anterior, es necesario considerar el contexto en el cual González Prada se insertó no sólo como intelectual, sino también como político. Inicialmente identificado en su período "radical-positivista" con el liberalismo, a su vuelta de Europa, este se le revela conservador, por varios motivos. Por su incapacidad de resolver los problemas que había diagnosticado antes de su partida -muy bien sintetizados en el "Discurso en el Politeama": las consecuencias de la guerra, la ausencia de la nación, la sociedad en crisis moral, la falta de integración del indio, etc.-, anteponiendo antes bien el cotidiano ejercicio del poder que redundaba en beneficio de la élite que lo usufructuaba y su aversión a transformarse con el objeto de dar solución a esos grandes dilemas del Perú. No hay diferencias de banderas entre los distintos partidos políticos, conservadores y liberales. ${ }^{26} \mathrm{El}$ liberalismo peruano es "un imposible social, un fenómeno tan inverosímil como el nacimiento de una ballena en un charco de ranas". ${ }^{27}$ Los políticos -hombres que "no dan lo que prometen"- y la política -insuficiente "para realizar el mayor bien sobre los individuos"28-, emergen como factores no de elevación, sino de regresión moral de la sociedad, de acuerdo a la muy buena síntesis que propone Delhom. ${ }^{29}$

Para este autor, el anarquismo de Prada constituye no una ruptura, sino más bien una continuidad de su pensamiento. El positivismo, de un lado, el antiautoritarismo y el individualismo, del otro, presentes en su temperamento ya desde ese segundo período, decantarán, como una suerte de consecuencia lógica o "culminación doctrinal última", en su etapa libertaria. La diferencia estriba, en todo caso, en el sujeto y el lugar desde donde parte el cambio: de las élites, propulsándolo desde arriba o de las masas, impulsándolo desde la base misma de la sociedad. Y también en el rol del intelectual, que como vimos varió significativamente, a causa de esa auto-transformación ideológica operada entre el Prada del siglo XIX y aquel del siglo XX.

\section{Anarquía versus Iglesia, Estado y Capital}

La notable producción de González Prada en la prensa libertaria peruana de principios de siglo XX, se concentró casi exclusivamente en el mensual Los Parias, donde entre 1904 y 1909 publicó más un centenar de trabajos. La dispersión que acarreó tal forma de aparición a lo largo de ese lustro -número a número, casi a "cuenta gotas", con su autoría oculta bajo seudónimos ("Luis Miguel"), iniciales cripticas ("L.M.", "S.D." y "D.S.") o el anonimato- quiso, logró ser resuelta en parte, con su posterior compilación.

Alberto González Prada, con la ayuda de un cuaderno de recortes periodísticos de su padre y una colección de Los Parias, reunió de forma póstuma sus escritos en prosa en dos libros: Anarquía (1936) y Prosa Menuda (1941). ${ }^{30}$ En el primero, aparecen los textos más teóricos o ideológicos en un sentido

25 González Prada, "La Anarquía", en Ibid. , pp. 17-18.

26 González Prada, "Dos virtudes" (1909), en Prosa Menuda, op. cit., pp. 199-201.

27 González Prada, "Liberalismo peruano" (1906), en Ibid., p. 137.

28 González Prada, "El intelectual y el obrero", en Anarquía, op. cit., pp. 72 y 74.

29 Joel Delhom, "Itinéraire idéologique d'un anarchiste latino-américain: Manuel González Prada (1844-1918)", en L'anarchisme a-t-il un avenir? Histoire de femmes, d'hommes et de leurs imaginaires, Actes du Colloque International de Toulouse, 27-29/10/1999, Lyon, ACL, 2001.

${ }^{30}$ En esos libros, fueron incluidos unos pocos artículos publicados en otros periódicos (algunos se desconocen precisamente en cuáles, por ejemplo, de los analizados aquí: "Luisa Michel" y "El crimen de Chicago") o inéditos, escritos por su autor en 1915 ("Alemania y su emperador") y entre 1910 y 1918 ("El deber anárquico", "La acción individual", "La policía" y "El individuo"). 
anarquista; son también, los más "universales". En el segundo, aquellos de "coyuntura", que tratan sobre algunos hechos y episodios producidos en el Perú, desde fines de siglo XIX hasta la primera década del XX. En la primera parte de este último libro, González Prada hijo coloca los de contenido anticlerical; en la segunda, los de temática política, económica y social. ${ }^{31}$

El discurso que emplea el autor en estos artículos es "de trinchera", el del panfleto y la polémica. La pompa y los recursos que adornaban sus anteriores ensayos son reemplazados por un estilo sencillo y agresivo. Prada quiere impactar, quiere conmover al lector, no busca ya persuadirlo, hacerlo razonar con argumentos bien formados. Con un objetivo: darle difusión y propaganda a las ideas anarquistas, a través de ese "periodismo de combate" que pondrá en práctica desde las páginas de Los Parias. ${ }^{32}$ Vale aclarar, ideas ya no en su versión "original", sino en el particular modo en que las había hecho suyas.

¿Qué entiende González Prada por Anarquía? Varias cosas. El intelectual busca con esa polisemia desterrar del imaginario las asociaciones negativas que existen en torno a la ideología anarquista: la no sociedad, el caos, la guerra, la barbarie primitiva. Así, su evolucionismo se plasma en la consideración de la Anarquía como una "etapa lógica de la evolución humana", un paso adelante y "no un salto regresivo a la selva prehistórica". 33 Pero además de ser un momento, es también medio y fin, camino y meta. La Anarquía es la revolución, en el terreno de las ideas y los hechos ${ }^{34}$, al tiempo que una "cumbre lejana", que marca el rumbo y a la que es necesario llegar. ${ }^{35}$ Esta, se relaciona con otra imagen recurrentemente utilizada: la de Anarquía como luz, que ilumina, que saca de la oscuridad a los hombres ${ }^{36}$ y que sirve también para divisar ese objetivo lejano, difícil de alcanzar y hasta quizás irrealizable, pero al que igual vale la pena aspirar:

La Anarquía es el punto luminoso y lejano hacia donde nos dirigimos por una intrincada serie de curvas descendentes y ascendentes. Aunque el punto luminoso fuese alejándose a medida que avanzáramos y aunque el establecimiento de una sociedad anárquica se redujera al sueño de un filántropo, nos quedaría la gran satisfacción de haber soñado. ${ }^{37}$

Además, en este artículo de 1907 que precisamente titula "La Anarquía", brinda una definición programática de lo que entiende por ella -quizás la única de toda su obra-, resumible "en dos líneas: la libertad ilimitada y el mayor bienestar posible del individuo, con la abolición del Estado y la propiedad individual". 38

El individualismo del liberalismo, luego del anarquismo de Prada, será una constante en su pensamiento. El individuo aparece asfixiado por la tríada explotadora y opresora que, para los teóricos clásicos del pensamiento libertario, Proudhon y Bakunin, encarnaba el principio de autoridad: la Iglesia, el Estado y el Capital. "Odiemos, pues, a las autoridades por la única razón de serlo: con el sólo hecho

\footnotetext{
A los fines de poder incluir estos artículos en el análisis, se optó por utilizar Anarquía y Prosa Menuda como fuentes primarias. Sin embargo, es posible consultar el mensual Los Parias, disponible en línea en el Archivo Digital FOPEP <http://www.archivofopep.org/materiales/periodicos-anarquistas-siglo-xx/los-parias/matriz-los-parias.html> (10/12/2018).

31 Los textos en verso de Los Parias, fueron también compilados en dos libros bien diferenciados por sus temáticas y estilos específicos. En 1909, González Prada publicó él mismo -sin revelar su identidad- sus estrofas anticlericales en Presbiterianas. Más tarde, su hijo reunió muchos de sus poemas (entre ellos, los aparecidos en el mensual anarquista) en Libertarias (1938).

32 Joel Delhom, "Manuel González Prada (1844-1918): del ensayo al panfleto", en Pacarina del Sur, año 3, n¹1, abril-junio 2012. Disponible en línea <http://www.pacarinadelsur.com/home/figuras-e-ideas/430-manuel-gonzalez-prada-1844-1918-delensayo-al-panfleto $>(11 / 10 / 2018)$.

33 González Prada, "La Anarquía" (1907), en Prosa Menuda, op. cit., p. 241.

34 González Prada, "El deber anárquico" (c. 1910-1918), en Anarquía, op. cit., p. 24.

35 González Prada, "Fiesta universal" (1905), en Ibid., p. 23.

36 González Prada, "Antipolíticos" (1907), en Ibid., p. 107.

37 González Prada, "La Anarquía", en Ibid., p. 19.

38 Ibid., p. 16.
} 
de solicitar o ejercer mando, se denuncia la perversidad en los instintos (...) El hombre verdaderamente bueno y libre no pretende mandar ni quiere obedecer". ${ }^{39}$

De hecho, planteándolo de forma esquemática, parecería ser que a medida que Prada se radicaliza, incorpora en las estaciones ideológicas que hemos identificado, una a una, a esas instituciones de poder, como objeto de oposición y crítica, como blanco de "propaganda y ataque".

La prosa, también los versos, de Prada son sinónimo de anticlericalismo, durante este período anarquista, así como en los anteriores.

En el artículo "El deber anárquico" publicado en Anarquía, sintetiza gran parte de su pensamiento. Allí dice sobre esta cuestión: "la Anarquía no se declara religiosa ni irreligiosa. Quiere extirpar de los cerebros la religiosidad atávica, ese poderoso factor regresivo". La religión es "hereje" de la Razón, es su antítesis, es la ignorancia del hombre. 40 Agrega en otro texto: es fanatismo e intolerancia. ${ }^{41}$ Pero además es una herramienta clave de dominación: "Al querer resolver en otra vida los problemas terrestres (...) el Cristianismo -de modo especial el Catolicismo- (...) siembra la resignación en el ánimo de los oprimidos (...) adormece el espíritu de rebeldía y contribuye a perpetuar en el mundo el reinado de la injusticia". 42

Continua toda su diatriba profana en Prosa Menuda. La crítica es igual de profunda hacia el clero: el "sacerdote romanista" y el "fraile español" -una temática en sí misma dentro de la obra antirreligiosa de González Prada, quien ve en el Perú contemporáneo una "frailocracia".43 Es total, general y particular, contra el dogma y las prácticas rituales; contra los personajes, santos y figuras "importantes"; con ello, también, contra los discursos religiosos. Se vale de todos los recursos retóricos a su alcance: desde el cuestionamiento incisivo que parte, a veces, de la teoría más abstracta, otras, de los hechos más cotidianos, hasta la sátira, llevada al extremo de la ridiculización y la burla. Con ellos, busca -¿lo consigue?- un efecto desacralizador.

La Iglesia es una institución todopoderosa, capaz de inmiscuirse en la política y la sociedad, subordinar y degradar al Estado y a las familias. "¡Oh tierra feliz donde el presbítero reina desde la calle hasta la alcoba!" exclama Prada. ${ }^{44}$ Hay una necesidad de separar estos ámbitos de la religión, de ponerlos al resguardo de su acción perniciosa.

"Cree derecho inalienable de la Iglesia el poder temporal". Esta clase relación se replica, desde Roma a Lima, desde los reyes italianos, que frente al papado "varían el ángulo de inclinación hasta el punto de barrer el suelo con la frente", a los gobernantes del Palacio de Lima, donde "gobierna el clero, y, sobre todo el clero, tiende a predominar el jesuita". La responsabilidad es de los devotos, "unos cuantos millones de bobos que tomen a lo serio el Catolicismo", pero fundamentalmente de la clase política, desde Víctor Manuel en Italia a los "nefandos" Eduardo de Romaña y Nicolás de Piérola en Perú. ${ }^{45}$ Lejos de contribuir sus gobiernos a la secularización -como era esperable-, aumentaron la sujeción al yugo católico.

La justicia, si es que la hay, actúa de acuerdo a un doble estándar: castigando con dureza los delitos cometidos a diario por el "borrachín de color honesto" y dejando impune las fechorías perpetradas por el "más zaparrastroso de los monigotes", el fraile. ${ }^{46}$ De esta manera, política y justicia permiten que los efectos de la religión, esa "enfermedad", se propaguen con mayor rapidez y eficacia al "cuerpo social".

A juzgar por la extensión que le dedica, la subsunción de la familia a los designios de la religión, parece preocuparle a González Prada más aún que el punto anterior. "Sobre algunas ideas conviene insistir a menudo, propalarlas diariamente, no olvidarlas ni un momento" aclara. ¿Qué ideas? "La

39 González Prada, "El Estado" (1904), en Ibid., p. 43.

40 González Prada, "El deber anárquico", en Ibid., p. 33.

41 González Prada, "Nuestros masones" (1907), en Prosa Menuda, op. cit., p. 67.

42 González Prada, "El deber anárquico", en Anarquía, op. cit., p. 33.

43 González Prada, "Perros" (1908), en Prosa Menuda, op. cit., p. 92).

44 González Prada, "Pidiendo bozal" (1906), en Ibid., p. 58.

45 González Prada, "Misticismo y terapéutica" (1906) y "Veinte de setiembre" (1907), en Ibid., pp. 60 y 74.

46 González Prada, "Pidiendo bozal", en Ibid., pp. 57-58. 
secularización de la escuela y de la familia: (...) levantar un muro infranqueable, poniendo de un lado al sacerdote, del otro a la mujer y al niño". ¿Por qué? El cura y el fraile no educan ni moralizan, son antes bien, la fuente de perversión: fanatizan y corrompen sexualmente a las esposas, viudas y beatas; "deforman" a sus educandos, "haciéndoles mancos de la voluntad, cojos del entendimiento, ciegos de la Razón", propagando el "amor unisexual" al abusar de ellos. ${ }^{47}$

Prada pone la lupa sobre víctimas y victimarios. Condena al clero, por su hipocresía, por su doble moral, el discurso versus la práctica. Critica a la mujer y explica al niño convertido en adulto, aquel que integrará "la muchedumbre" -políticamente analfabeta, fácilmente manipulable-, por actuar como agentes reproductores de esa influencia nociva, tanto en el ámbito doméstico como público.

La mirada de Prada sobre la condición femenina es fundamentalmente negativa. "Cuidado con ellas" llama un artículo de 1906 donde dice "la mujer, salida del templo y desligada del sacerdote, representa el más elevado tipo en la evolución femenina; por el contrario, la frecuentadora de iglesias y colaboradora de frailes o de clérigos (...) es el adversario social y doméstico".48 Pese a estas palabras, que se reproducen incluso con mayor dureza en otros pasajes de su obra, hay un rescate potencial de tal condición, en tanto existe una posibilidad de redención moral y social, sinónimo en un poema publicado en Los Parias de rebelión política. ${ }^{49}$

Al sustrato anticlerical del discurso de Prada, planteado ya en los años de "formación", se superpone luego la crítica a la política burguesa ("una religión sólidamente organizada" señalará como analogía ${ }^{50}$ ), la cual, como vimos, se funda en dos razones y explica el salto del período "radical-positivista" al "radical-anarquista". Ese cuestionamiento forma parte, en esta nueva etapa, de un golpe que pretende ser demoledor: contra el Estado, del que los anarquistas se declaran "enemigos", y contra todo su andamiaje institucional, normativo y coercitivo. ${ }^{51}$

En este punto de su trayectoria ideológica, el pensador ha llegado al entendimiento que la "redención social" no viene de "los políticos", sino que "de ellos provienen los mayores obstáculos para llegar al reino de la justicia".52 De ahí, la reivindicación de un "grito salvador (...) ¡Guerra a la política!" y la advertencia que tenga para hacerle a los trabajadores: "una cosa son los intereses de la política y otra cosa los intereses del proletariado". La política de los partidos, también la de la mutualista Confederación de Artesanos Unión Universal, es una gran puesta en escena: enrolarse en "banderías", subir al "tabladillo electoral", poner el "voto en el ánfora de una plazuela", de nada sirven, pues los políticos y sus partidos no se interesan, no hacen nada en "un conflicto grave entre el capital y el trabajo [como] se ve hoy mismo". ${ }^{33} \mathrm{El}$ "proletario noble y activo" no forma parte de ese circo que lo debilita: "se subleva o se abstiene". ${ }^{54} \mathrm{Da}$ la pelea, como los huelguistas del Callao en 190455; se organiza y robustece contra aquella farsa, como los panaderos de la Federación Obrera Estrella del Perú en 1905.56

El Parlamento es el ámbito por excelencia donde se mueven esta clase de hombres. La política parlamentaria, los anula, los envilece, promueve en ellos el "abuso de poder" sin importar su procedencia partidaria. Nadie escapa a esta "inclinación general": ni los socialistas, ni los propios obreros. Por ese motivo "todo gobierno es malo y toda autoridad quiere decir tiranía". Pero esa característica intrínseca del parlamentarismo está cubierta con un velo, la "gran superstición política de hoy: el derecho divino de

47 González Prada, "Sesenta por ciento" (1905), en Ibid., pp. 19-20.

48 González Prada, "Cuidado con ellas" (1906), en Ibid., p. 54.

49 Manuel González Prada, "El himno de las mujeres" (1907), en Libertarias, París, Tipografía de Louis Bellenand et Fils, 1938, pp. 81-83.

50 González Prada, "El deber anárquico", en Anarquía, op. cit., p. 35.

51 González Prada, "El Estado", en Ibid., p. 40.

52 González Prada, "Un aniversario" (1905), en Prosa Menuda, op. cit., p. 100.

53 González Prada, "Antipolíticos" (1907), en Anarquía, op. cit., pp. 107-108.

54 González Prada, "La 'confederación de artesanos" (1906), en Prosa Menuda, op. cit., pp. 135-136.

55 González Prada, "Antipolíticos", en Anarquía, op. cit., p. 108

56 González Prada, "La 'confederación de artesanos', en Prosa Menuda, op. cit., p. 136. 
los parlamentos" que, según el citado Herbert Spencer, vino a reemplazar al de los reyes de ayer. Por ello, el "voto de la muchedumbre" ocupa el mismo lugar, en términos de utilidad, también de legitimidad, que antiguamente tenía la unción sacerdotal. ${ }^{57}$

¿Qué significa en términos concretos el abuso de poder practicado por los congresales? Significa no luchar por las ideas, pelear sí por los negocios y acordar cuando se trata del provecho común. Significa "imponer contribuciones y patrocinar iniquidades"58 a través de "leyes de excepción y (...) gabelas que gravan al que posee menos". 59

Sobre este punto, Prada considera la utilidad y verdadera función de la ley y consecuentemente, el rol que cumple la justicia. "El Estado con sus leyes penales, la Iglesia con sus amenazas póstumas, no corrigen ni moralizan". ${ }^{60}$ Sirven tal vez para dirimir cuestiones entre ricos, para proteger sus privilegios, dicho de otro modo. Para los pobres las leyes son sinónimo de "sanción de los abusos inveterados"61; para ellos "no se admite más ley, más juez ni más árbitro que la fuerza"62: el encarcelamiento, la deportación, el fusilamiento ${ }^{63}$; la represión de la huelga y la masacre, como la de Santa María de Iquique en 1907.64

"¿Quiénes viven predicando el religioso respeto a la ley?" Los poderosos: "el gobernante que la viola, el abogado que la tergiversa, el juez que la vende y el bribón que la compra". Por eso, González Prada llama a la desobediencia civil: a desconocer el "óleo" con que la ley viene "ungida del Parlamento". El individuo que "estima el valor de su personalidad (...) la examina, la somete al análisis de su pensamiento, y si la juzga buena, la cumple; si no, la rechaza". ¿Por qué? Como enseñó la Revolución Francesa, "ley injusta no se cumple ni se acata". Se trata de un derecho, el de protestar y sublevarse. Ese es el camino para ejercer el "libre examen político y social", primer paso emancipador hacia "una sociedad bien organizada" donde las leyes aseguren "el derecho de todos, impidiendo que las agrupaciones y los individuos queden sacrificados al interés de agrupaciones más numerosas o de individuos más influyentes". .5

Dos procesos judiciales son casos testigos, el de los mártires de Chicago y el de Dreyfus, sobre cómo funciona la justicia "cobarde y servil" en las cinco partes del mundo. Justicia civil equivale a justicia militar. "No tiene más misión que defender al capital (es decir, al robo) y servir al Estado (es decir, a la fuerza)", y para ello no dudará en sacrificar a hombres inocentes como aquellos, en pos de mantener un orden social basado en la explotación del más fuerte. La justicia procede así, con el mismo doble estándar ya señalado en relación a la Iglesia, beneficiando siempre a los poderosos: "en el Perú, la vemos absolver a los criminales adinerados $(. .$.$) y condenar sin misericordia al negro, al indio desheredado y al desertor$ inconsciente".66

Del mismo modo, la fuerza pública, la policía y el ejército, aparecen al servicio de la Iglesia, la política y los "gobiernos abusivos", la "sociedad burguesa" y los patrones. Prada analiza por separado ambas instituciones, no ahorra en reflexiones negativas sobre su función eminentemente conservadora y represora, destinada a mantener a punta de macana y sable la paz social. Una amenaza del orden público necesariamente "exige medidas de represión (...) Si la huelga adquiere proporciones alarmantes y posee la fuerza suficiente para arrollar al polizonte o guardia civil, entonces acude el soldado". ${ }^{67}$

57 González Prada, "El deber anárquico", en Anarquia, op. cit., pp. 35-36.

58 González Prada, "El empréstito" (1906), en Prosa Menuda, op. cit., p. 141.

59 González Prada, "El intelectual y el obrero", en Anarquía, op. cit., p. 74.

${ }^{60}$ González Prada, "El individuo", en Ibid., p. 158.

61 González Prada, "El deber anárquico", en Ibid., p. 37.

62 González Prada, "Las dos patrias" (c. 1908-1909), en Ibid., p. 147.

63 González Prada, "El Estado", en Ibid., p. 38.

${ }^{64}$ González Prada, "Las dos patrias", en Ibid., p. 146.

65 González Prada, "El libre pensamiento y la ley" (1905), en Prosa Menuda, op. cit., pp. 124-125.

66 González Prada, "El crimen de Chicago" (c. 1904-1909), en Anarquía, op. cit., p. 131.

${ }^{67}$ González Prada, "Cambio de táctica" (1905), en Ibid., p. 54. 
Esa policía, "la más odiosa de las instituciones sociales", se basa "en el espionaje, la delación, el soborno y la tortura", es "la encargada de proveer cárceles, penitenciarías, galeras y patíbulos". González Prada insiste en listar sus crímenes: "persigue a los adversarios del gobierno, inventa conspiraciones, practica el chantaje, provoca motines, apalea escritores, arrasa imprentas, viola mujeres, tortura presos, hurta lo robado, asesina en los caminos al culpable y al inocente". Por eso, algunas veces llega a ser "el gendarme más útil que el soldado". Es un comportamiento corporativo "de maffia o de camorra", que atraviesa toda la cadena de poder -"desde el Ministro de Gobierno hasta el soplón"-, e internacional: desde Francia y España, hasta el Perú. Al agente de policía peruano, el "cachaco", le reserva el peor lugar de todos: "nadie más abusivo, más altanero ni más inexorable" que él.

Este, para el autor, comparte varias características con el soldado raso -dos figuras que en su discurso parecen intercambiables. La "bajeza ante el superior" y la "altivez con el inferior" en el escalafón de la fuerza, que se proyecta en la estructura jerárquica de la sociedad. De ahí, que no lamente, más bien se regodee ir en contra de los suyos, de su clase, de su familia.

Sobre el policía, dice: "Nace del pueblo, vive en la intimidad con la muchedumbre, conoce las miserias de los desheredados, y se declara su enemigo implacable (...) ¡Con qué regocijo descarga su rifle contra el pecho de un huelguista inerme! ¡Con qué delicia palomea desde una torre al revolucionario vencido". ${ }^{68}$ Sobre el soldado, agrega: "Ese heroico defensor del orden público descarga el rifle, sin averiguar por qué ni sobre quién, importándole un bledo que la bala hiera al amigo, al hermano, al padre o al hijo".69

Prada duda acerca de cuál personaje le genera más odio. "En nadie se palpa tanto la influencia de la autoridad como en el soldado"..$^{70}$ Pero de nuevo, no es un asunto individual; como en la policía, existe un espíritu de cuerpo, resultante de la cadena de poder compuesta de diferentes eslabones: "por abusivos y despóticos, por inflados y soberbios, por inhumanos y crueles, todos los portadores de sable son igualmente aborrecibles, desde el gran mariscal (..) hasta el cabo instructor". ${ }^{11}$ González Prada aborda en esos dos artículos tempranos, de 1904 y 1905, el porqué de esta actitud. Contrariamente a lo que muchos plantean, el servicio militar no es una "escuela de civilización", es una institución donde todo lo que hay en ella -desde la instrucción que recibe la tropa, hasta los lugares donde habita y entrena (el "cuartel", la "caserna" o "canchón" y el "patio") y la ropa que utiliza (la "casaca")- primitiviza, embrutece y salvajiza. La conversión de paisano a soldado es una "metamorfosis a la inversa", que degenera al hombre: se le "atrofia el cerebro"72 y "se transforma en un animal adiestrado para embestir a sus compañeros"; se convierte en una máquina, automática y de gran precisión, indiferente, incapaz de sentir dolor. ${ }^{73}$ Con esta explicación González Prada está lejos de querer justificar. Construye un argumento con el que pretende ser más profundo e incisivo aún en su crítica.

El mismo efecto causado por el ejército en los reclutas, se replica en la sociedad, pues este -como la política y la religión- es un factor de regresión: "la Humanidad avanza muy lentamente, porque al acelerar el paso, tropieza en las redes de un sacerdote o se hiere en la bayoneta de un soldado". Hay una diferencia entre ambos, explícita y reiterada: "el reino del sacerdocio declina: el imperio de la milicia no da señales de concluir". Así, el primero es mucho menos dañino, en las atrocidades que comete, pero sobre todo menos eficaz para erigirse en pilar del statu quo. "La sociedad burguesa puede compararse a un vetusto edificio que amenaza ruina. Los nobles, los capitalistas y los sacerdotes son apolillados y endebles puntales que nada sostienen; las columnas de hierro macizo, los que impiden el derrumbamiento

\footnotetext{
68 González Prada, "La policía" (c. 1910-1918), en Ibid., pp. 135-138.

${ }^{69}$ González Prada, "Cambio de táctica", en Ibid., p. 54.

70 González Prada, "El sable" (1904), en Ibid., p. 47.

${ }^{71}$ González Prada, "Cambio de táctica", en Ibid., p. 55.

72 González Prada, "El sable", en Ibid., pp. 48-51.

73 González Prada, "Cambio de táctica", en Ibid., p. 54.
} 
final son los militares". ${ }^{74}$ Esa es la importante misión que estos, a sablazos, vienen a cumplir: impedir que esa ruina se encamine hacia la revolución, y esta, hacia la Anarquía.

González Prada entiende bien la unidad que hay entre conflicto interno y externo, pues según él, los gobiernos se valen de invocar "el amor a la patria" en guerras propias y ajenas para arrojar "una ducha helada sobre el calor tórrido de los más levantiscos". ${ }^{75}$ Repara también sobre sus consecuencias. No son una "hazaña gloriosa"; son antes bien, el "degüello de naciones enteras", una "barbarie prehistórica". Quienes las conducen y llevan adelante, "héroes oficiales" y guerreros anónimos, no son más que "degolladores de reses humanas" y asesinos, verdaderos bárbaros. ${ }^{76}$

El antimilitarismo de Prada, se sustenta como ya vimos en el anticapitalismo y también, en el internacionalismo, "inconciliable" este último con el "patriotismo". El autor dice en 1906, en un plural en el que se incluye, no tener patria y no ser patriota. "El socialismo, a pesar de creerse desvinculado de todas las religiones, se funda en una máxima cristiana: todos somos hermanos". De esta conclusión se deriva una lección, contraria a la posición de "obediencia pasiva" de los socialistas franceses y alemanes: "sólo acabarán los ejércitos y, por consiguiente, las guerras cuando los hombres no se resignen a sufrir el yugo militar, cuando la mayoría de los llamados al servicio tenga el suficiente valor para rebelarse, invocando el generoso principio de la fraternidad". ${ }^{77}$

Tiempo después, profundizando la anterior argumentación y añadiéndole un sentido clasista, escribirá: "[Karl] Liebknecht dijo: "En el mundo no hay sino dos patrias: la de los ricos y la de los pobres". Todas las naciones son iguales; las de Europa, las de la "América republicana", están divididas en dos grandes clases sociales: de un lado están los poseedores, del otro los desposeídos. ${ }^{78}$

Sin embargo, a propósito de esta idea, González Prada caracteriza la configuración social particular de Chile y Perú, e inevitablemente, aparece un tema espinoso, el de la Guerra del Pacífico. Y con él, la tensión con los anteriores tópicos, el antimilitarismo y el internacionalismo. Predomina en ella, una mirada teñida de revanchismo. Inevitable para los hombres de su generación, pero inadmisible en algunos tramos para quien se define como anarquista.

Ya en 1901 planteaba que al país victorioso, Chile, le cabía "la obligación de cubrir los gastos de guerra, indemnizar los daños y perjuicios, ceder una faja de su territorio y signar el tratado impuesto por el vencido". Hace la salvedad, sin embargo: "si hay la perfidia y la iniquidad chilenas, hubo también la perfidia y la iniquidad peruanas" hacia Bolivia y Ecuador. ${ }^{79}$

Entre 1908 y 1909, en el texto referido -"Las dos patrias"- y "La huelga de Iquique", este reciente suceso le sirve de excusa para volver a la maldita guerra. Tres son los actores de estos dos episodios. La clase dominante, que habría desencadenado el conflicto y la masacre. El "poseedor" o "hacendado chileno", que comparte intereses comunes con otros "grandes ladrones" (el azucarero peruano, por ejemplo), "una casta esparcida en el globo (...) estrechamente unida y juramentada para luchar con su enemigo común: el proletario". El gobierno de Chile y su brazo militar, al servicio de aquella "clase-casta", que aparece en la guerra como el que "arrebató" las salitreras al Perú, y este como "vecino desvalijado". Y finalmente, los "rotos chilenos", protagonistas de esa "asoladora invasión de bárbaros". Si bien feroces, perpetradores en tierras peruanas de robos, incendios, violaciones y asesinatos, Prada vuelve a matizar y los exculpa. Fueron movidos a ello por sus jefes, y estos, por las "clases dominadoras", cuya propia ferocidad acababa de ser confirmada en el trágico desenlace de la huelga. La paradoja es que los muertos

\footnotetext{
${ }^{74}$ González Prada, "Cambio de táctica", en Ibid., p. 55.

75 Ibid., p. 52.

76 González Prada, "El sable", en Ibid., pp. 49-50.

77 González Prada, "Rebelión del soldado" (1906), en Ibid., pp. 99-100.

78 González Prada, "Las dos patrias", en Ibid., p. 144.

${ }^{79}$ González Prada, "Rebelión del soldado" (1906), en Ibid., pp. 165-166.
} 
de Iquique, los obreros incapaces "de ver que el negocio no tiene patria", habían sido utilizados en la guerra como "el arma o el brazo del ladrón". 80

La tensión se convierte, en algunos pasajes de su obra, en contradicción irresuelta. Primero, cuando entre 1905 y 1906, González Prada reivindica al Coronel Francisco Bolognesi, un héroe de la Guerra del Pacífico y se pregunta por la "gratitud nacional" -ausente- que le era debida a este por el pueblo peruano. ${ }^{81}$ ¿El héroe de guerra no era una figura denostable, un "degollador" según había dicho más o menos contemporáneamente? Igualmente, cuando hace explícito su profundo anti-germanismo, que emana del emperador alemán y sus instituciones imperiales emergentes de otra guerra de "arrebato", la franco-prusiana. De la "ferocidad teutónica" desplegada en el exterior ${ }^{82}$ y del autoritario régimen instaurado entre su población, asimilada a "una aglomeración de seres moralmente emasculados", carentes de "voluntad (...) sometidos a la obediencia pasiva". ${ }^{33}$ Este sentimiento, en el contexto de la Primera Guerra Mundial, lleva a Prada a inclinarse -sin definirse abiertamente, como Kropotkin, Jean Grave y Paul Reclus, firmantes del "Manifiesto de los Dieciséis"- por el bando de los "ejércitos aliados", en contra del "ejército del Káiser". ${ }^{84}$ En 1915, al mundo dividido en dos patrias, se le superponía así una nueva división "en dos categorías de seres: los humanos y los alemanes"85, lo cual complejiza tanto a ese mundo, como al pensamiento de quien concibe a este.

Esta aseveración tardía, tomada del británico Rudyard Kipling, no debe opacar algunas de las más importantes consideraciones de González Prada acerca de su tercer enemigo principal, aliado a los otros dos: el Capital.

El autor indaga sobre la naturaleza de la explotación capitalista. Hay un intento de historizar algo que es esencialmente una relación, establecida entre dos: vencedores y vencidos. "Esclavitud, servidumbre y proletariado son la misma cosa, modificada por la acción del tiempo. Si en todas las naciones pudiéramos reconstruir el árbol genealógico de los proletarios veríamos que descienden de esclavos o de siervos, es decir, de vencidos". ${ }^{86}$ ¿Cuál es la diferencia entre los dos primeros? Mientras el amo esclavizaba sobre la base de la coacción ("el derecho de la fuerza"), el capitalista y el "letrado" explotan al proletario "ignorante" a través del consenso: "predicando la evangélica máxima del amor al prójimo, hablando de libertad, igualdad y fraternidad". ${ }^{87}$ Sin embargo, a través de los tiempos, la explotación ha sido y sigue siendo la misma cosa: "donde hay cambio de dinero por fuerza muscular, donde uno paga el salario y el otro le recibe en remuneración de trabajo forzoso, ahí existe un amo y un siervo, un explotador y un explotado". ${ }^{88}$ Una definición amplia de explotación, que incluye a los trabajadores de la ciudad y el campo, pues los dos trabajan para que otros descansen y producen para que esos mismos disfruten del beneficio: "los dueños de fábricas y de haciendas", "los monopolizadores del capital y de la tierra", "los que se llaman industriales porque ejercen el arte de enriquecerse con el sudor y la sangre de sus prójimos". ${ }^{89}$ Pero mientras "los ricos y señores" se enriquecen, "los pobres y jornaleros" se empobrecen, debiendo luchar para asegurar su subsistencia. ${ }^{90}$ Es decir, se trata de una relación dialéctica la de explotadorexplotado y la de riqueza-pobreza, definida desde una óptica materialista. ${ }^{11}$

80 González Prada, "Las dos patrias", en Ibid., pp. 146-147 y González Prada, "La huelga de Iquique" (1908), en Prosa Menuda, op. cit., pp. 243-244.

81 González Prada, "Las fiestas" (1905) y "Gratitud nacional" (1906), en Prosa Menuda, op. cit., pp. 119-121 y 131.

82 González Prada, "Ferocidad teutónica" (1906), en Anarquía, op. cit., pp. 79-82.

83 González Prada, "Alemania y su emperador" (1915), en Prosa Menuda, op. cit., pp. 245-249.

${ }^{84}$ Delhom, "Itinéraire idéologique...", op. cit.

85 González Prada, "Alemania y su emperador", en Prosa Menuda, op. cit., p. 245.

86 González Prada, "Primero de mayo" (1907), en Anarquía, op. cit., p. 102.

87 González Prada, "Primero de mayo" (1909), en Ibid., p. 162.

88 González Prada, "Primero de mayo" (1906), en Ibid., p. 83.

89 González Prada, "Primero de mayo" (1907), en Ibid., p. 101.

90 González Prada, "Política de negocios" (1909), en Prosa Menuda, op. cit., p. 196.

${ }_{11}$ Hay que aclarar que el pensamiento de Prada se va perfilando en esta dirección, sólo con el correr de los años. En 1906, plantea por ejemplo que "los obreros no gozan el triste privilegio de ofrecer las víctimas. La sociedad es una inmensa escala de 
Las consecuencias de la explotación son realmente graves, pues como las instituciones encarnadas en el religioso, el político o el militar, actúan como un factor regresivo en lo moral y social. El trabajo manual ya no "dignifica" ni "engrandece" al hombre. Es, al contrario, "indigno" de él. El régimen lo "degenera", lo deshumaniza (vuelve a esta idea), al punto de convertirlo en un animal de carga, o incluso, algo inferior, una máquina sin "ilusión de mejorar en su desgraciada existencia" y sin "instinto de rebelión", capaz de volverse "contra nosotros para defender a su verdugo y a su Dios: el capitalista".92

¿Cuál es el punto de origen de esta alienación, que se retroalimenta día a día? El "robo legalmente organizado"93, del trabajo y el dinero ajenos. Por eso "toda iniquidad se funda en la fuerza"94, en "la agresión latente de los poseedores contra los desposeídos"95. La propiedad, ella misma es un robo dice como Proudhon- González Prada, llevando esa proposición al extremo cuando señala en 1905 ante la audiencia obrera del Politeama "la propiedad es el asesinato". ${ }^{96}$ En la historia, el autor también halla una propuesta: "La Humanidad de ayer produjo y capitalizó [los bienes materiales, las ciencias, las artes y las industrias]; a la Humanidad de hoy toca recibir la herencia: lo de todos pertenece a todos". ${ }^{97}$ Así pues, si bien en la definición de Anarquía que da en 1907 hay una apuesta por la "propiedad individual", en su última etapa, la del "El Deber Anárquico", negará el "régimen individualista" y se pronunciará por la propiedad colectiva. ${ }^{98}$

González Prada, sagaz, analiza su época y advierte la novedad, como si se tratara de un salto dado hacia adelante por un capitalismo en permanente transformación: el imperialismo.

"Cuando oigamos decir que una nación se enriquece, debemos entender que en ella se forma una clase disfrutadora de todos los beneficios", lo cual conlleva el "monopolio" de los negocios y el "acopio" de ganancias" de los "privilegiados", la pobreza del "gran número". "Estados Unidos, el país de los multimillonarios, es la tierra de la más espantosa miseria. Es también la nación del imperialismo en cierne, pues las clases dominadoras, una vez lanzadas a la política de negocios, acaban por volverse rapaces y agresivas en el exterior". ${ }^{99} \mathrm{El}$ autor reconoce y devela al imperialismo no sólo en Estados Unidos y sus grandes trusts, sino también en los de Francia, Gran Bretaña y Alemania, a través de sus intervenciones en el Perú: el contrato Dreyfus (1869), el contrato Grace (1888) y el empréstito del Banco Alemán Transatlántico para la construcción de ferrocarriles (1906). ${ }^{100}$ Del mismo modo, describe la funesta actuación del capital financiero, mediante sus redes de poder tendidas desde Estados Unidos (el "multimillonario Rockefeller") hacia su país (los banqueros y financistas locales). ${ }^{101}$ Las consecuencias saltan a la vista: ausencia de la soberanía del gobierno en algunos territorios (el caso de la selva peruana, a causa de la presencia de la Inca Rubber Co. ${ }^{102}$ ) y descalabros económicos, producto de las recurrentes

iniquidades (...) hasta los opresores y explotadores necesitan verse emancipados de sí mismos porque son miserables esclavos sujetos a las preocupaciones de casta y secta" (González Prada, "Primero de mayo" [1906], en Anarquía, op. cit., p. 85). Esta mirada conciliadora e idealista, en la que la alienación de la sociedad capitalista alcanza por igual a oprimidos y opresores, es reemplazada a veces, matizada otras, por un discurso más "duro" que manifiesta en sus artículos posteriores como, por ejemplo, el último citado de 1909.

92 González Prada, "Primero de mayo" (1909), en Ibid., pp. 163-164.

93 González Prada, "Primero de mayo" (1906), en Ibid., p. 83.

${ }^{94}$ González Prada, "Primero de mayo" (1909), en Ibid., p. 164.

95 González Prada, "La acción individual", en Ibid., p. 126.

${ }^{96}$ González Prada, "El intelectual y el obrero", en Ibid., p. 76.

${ }_{97}$ González Prada, "El deber anárquico", en Ibid., pp. 31-32.

98 Sobre este tema, véase: Delhom, Joel, "Manuel González Prada et le régime de la propriété. Idées radicales et esthétique d’une sémiotique intertextuelle de propagande", en Revue Amerika - Dossier "En torno a Manuel González Prada: el pensamiento radical como fermento literario y social", $\mathrm{n}^{\circ} 17$, Université Rennes 2, Haute Bretagne, 2018. Disponible en línea $<$ https://journals.openedition.org/amerika/8393> (10/12/2018).

99 González Prada, "Política de negocios" (1909), en Prosa Menuda, op. cit., p. 196.

100 González Prada, "El empréstito", en Ibid., pp. 139-140.

101 González Prada, "La crisis monetaria" (1906), en Ibid., pp. 163-164.

102 González Prada, "Los verdaderos salvajes" (1905), en Ibid., pp. 111-112. 
tomas de empréstitos y crisis monetarias. ${ }^{103}$ Advierte la connivencia del "mundo de la política" con este capitalismo de nuevo cuño, también.

\title{
¿Caerá la tríada explotadora y opresora?
}

El pesimismo de González Prada acerca de las posibilidades de acabar con el poder de la Iglesia, contrasta con su optimismo en relación al destino que le depara al Estado y al Capital.

El primero es un problema de muy difícil solución. En dos artículos de 1908 y 1909 dice que no hay "esperanza de redimirnos", no se "vislumbra el simple amago de una luz". No basta con la ciencia y la filosofía como antídotos. ${ }^{104}$ Considera opciones más radicales: la "degollina", la "expulsión". No lo convencen, no son suficientes. Tampoco que la alternativa venga desde dentro, pues "en el Perú el Gobierno y los ciudadanos giran bajo la razón social de 'Sotana y Compañía"'. ${ }^{105}$ Todas las instituciones, todas los partidos políticos, están "enfrailados". ¿Entonces? Sorprendentemente propone: así como la "mano ajena" de Bolívar y Sucre intervino en la primera liberación de Perú, la de los españoles, aquella de "las naciones vecinas acudirán a desinfectarle, no por amor a nosotros sino por interés de ellas mismas: practicarán una obra de higiene internacional", en lo que será, espera, "una segunda emancipación: la de las conciencias". ${ }^{106}$

En la visión de Prada, parecería ser que la capacidad y tenacidad de las instituciones eclesiásticas para construir hegemonía a lo largo de siglos y siglos de dominación, en el mundo y particularmente, en el Perú, son superiores a las del Estado y el Capital. De ahí que, poco a poco, el parlamento y el ejército, sean cuestionados: "las asambleas legislativas (...) van perdiendo su aureola divina y convirtiéndose en objetos de aversión y desconfianza, cuando no de vergüenza y ludibrio", "existen pueblos donde se verifica una huelga de electores" 107 ; "el legendario prestigio de la casaca va desapareciendo"108, "ya no parece eterno el reinado del soldadote. Cayendo los puntales, ¿qué será de toda la fábrica? El edificio está más apolillado de lo que se piensa". ${ }^{109}$

Lo mismo parece suceder con el régimen capitalista. La "sociedad burguesa" está en "ruinas". "Felizmente" como dice el autor a propósito del $1^{\circ}$ de mayo de 1909, los trabajadores peruanos se preparan para dar el golpe final:

\begin{abstract}
Se congregan hoy para recordar a los buenos luchadores que señalaron el camino y para reconocerse, estrechar las filas, cambiar ideas y acelerar el advenimiento del gran día rojo. Y decimos rojo, pues no incurriremos en la ingenuidad o simpleza de imaginarnos que la Humanidad ha de redimirse por un acuerdo amigable entre los ricos y los pobres, entre el patrón y el obrero, entre la soga del verdugo y el cuello del ahorcado. Toda iniquidad se funda en la fuerza, y todo derecho ha sido reivindicado con el palo, el hierro o el plomo. Lo demás es teoría, simple teoría. ${ }^{110}$
\end{abstract}

El primer golpe, lo había dado Manuel González Prada con sus escritos en la prensa. A su juicio, se trataba de "simple teoría". Lo importante vendría, después: la acción, que según defenderá en otros escritos, es acción directa. La violencia legítima, el atentado, la huelga general armada, el sabotaje... La pregunta es si puede pensarse la una sin la otra. Él, ya había dicho que no.

103 González Prada, "La crisis monetaria", en Ibid., p. 163.

104 Delhom, "Itinéraire idéologique...", op. cit.

105 González Prada, "Nuestra razón social" (1909), en Prosa Menuda, op. cit., pp. 94-95.

106 González Prada, "Por mano ajena" (1908), en Ibid., pp. 88-89.

107 González Prada, "El deber anárquico", en Anarquía, op. cit., p. 36.

108 González Prada, "El sable", en Ibid., p. 50.

109 González Prada, "El crimen de Chicago", en Ibid., p. 133.

110 González Prada, "Primero de mayo" (1909), en Ibid., p. 164. 


\section{Conclusión}

A modo de conclusión, podemos sugerir que la redacción de los artículos aquí analizados, implicó de parte de su autor, un gran y doble esfuerzo.

Primero, de interpretación y de reelaboración ideológica, de fuentes anarquistas, y también, muchísimas, no anarquistas. Manuel González Prada fue un pensador heterodoxo. En efecto, en este proceso convergieron sus distintos períodos. No se puede concebir la evolución de sus ideas dividida en compartimientos estancos, sino que esas diversas tradiciones pervivieron en el último Prada, aquel del siglo XX. La capacidad de este, residió justamente en conciliarlas, a veces, desde la tensión solapada, otras, desde la contradicción abierta. Así lo ilustran, varias "trazas ideológicas" que afloran de su escritura -más anárquica, que pura, doctrinariamente anarquista-, como una suerte de rastro o vestigio de su sinuoso pasado intelectual.

Por ejemplo, el liberalismo, con el acento puesto en el individuo, la nación peruana que no pudo ser (y su posición ¿revanchista? sobre la Guerra del Pacífico, derivada de esta ausencia). El positivismo, con su impronta evolucionista y determinista, que lo lleva a plantear muchas veces una mirada negativa respecto de la agencia y potencialidad revolucionaria de los trabajadores, sintetizada en el difícil e interesante concepto de "la muchedumbre" -el cual merece ser explorado con mayor profundidad. Incluso, el catolicismo -en el que fue criado y al que combatió desde el inicio- en el que se enraízan simbólicamente los valores éticos-morales que pondera y las máximas cristianas que destaca.

Segundo, fue la suya una apuesta comunicativa y de difusión, que explica esa incansable colaboración con el mensual limeño. González Prada intentó provocar a su audiencia, hacerla permeable a su mensaje, de ahí la forma de su discurso, su estilo. También, traducir, en el sentido de hacer inteligible el pensamiento libertario entre la naciente clase trabajadora del Perú, de ahí su contenido.

Lo anterior, no le quitó riqueza conceptual, más bien se la añadió a su pensamiento. Ejemplo de ello es el carácter polisémico de la palabra Anarquía, lo mismo que la consideración de esa tríada explotadora y opresora, cuyos componentes no son pensados por separado, sino en la retroalimentación mutua de sus efectos de poder. La Iglesia, a través del dogma y sus agentes, el Estado, a través del consenso (la política) y la coerción (la corporación militar), el Capital, a través de la explotación, no sólo apuntalan el statu quo. Todos ellos tienden a un único y mismo destino en términos evolutivos: la regresión moral y social de la especie humana, que merced a ella, deja de ser tal, se degenera, se deshumaniza. El camino contrario hacia su perfeccionamiento, hacia su plena realización como tal: y aquí, volvemos al punto de partida de nuestro análisis, la Anarquía, esa doctrina que define como humanitaria.

Pese a su heterodoxia, a sus tensiones y contradicciones, el pensamiento de la última etapa de Prada constituye una unidad coherente en cuanto "todo complejo". La dificultad de abordarlo y entenderlo como tal reside no sólo en lo anterior, sino además en el carácter fragmentado y disperso con que fue puesto por escrito y publicado originalmente.

Otro aspecto que comprueba esta complejidad, tiene que ver con que esa profundidad teórica e ideológica, no fue en desmedro, antes bien potenció una lectura, una interpretación de la realidad económica, social, política- peruana que le era contemporánea al autor, a la luz de esos temas y motivos anarquistas, tal como surge de los artículos que componen su Prosa menuda.

González Prada, pudo, no quiso ser en esta etapa de su trayectoria, un intelectual incomprensible, ubicado en las alturas. De hecho, este momento, donde más escribe y más publica, no casualmente coincide con el despertar del movimiento libertario local a través de la creación, a lo largo y ancho del país, de numerosos centros de estudios sociales, también de algunos sindicatos. Prada se convierte en esta etapa formativa del proletariado del Perú, en una voz autorizada, que seguirá siendo citada luego de su muerte en 1918: con sus textos vueltos a reproducir en La Protesta de Lima; con grupos que hacen suyo su nombre. Esa voz será retomada, no sólo por anarquistas, sino por figuras de las más variadas 
tendencias ideológicas: José Carlos Mariátegui, Víctor Raúl Haya de la Torre, por ejemplo. En cuanto líderes del comunismo y del aprismo respectivamente, se acercan y se distancian de ella, en un mismo acto. Pero no dejan de absorber, de nutrirse de su influencia.

Quizás, esa trascendencia, sea una muestra del gran aporte que Manuel González Prada realizó para allanar las conciencias y promover la emancipación de "los parias" del Perú. Haya de la Torre lo llamaba "Maestro". Pensador heterodoxo y complejo, sí, pero también maestro. Eso, es lo que precisamente fue.

\section{Bibliografía}

\section{Libros artículos y comunicaciones}

Ballivian, Jesus, Anarchism and the press in Lima. The case of Los Parias, Thesis submitted for the degree of Master of Arts in Latin American Studies, University of Illinois, 2010.

Delhom, Joel, "Itinéraire idéologique d'un anarchiste latino-américain: Manuel González Prada (18441918)", en L'anarchisme a-t-il un avenir? Histoire de femmes, d'bommes et de leurs imaginaires, Actes du Colloque International de Toulouse, 27-29/10/1999, Lyon, ACL, 2001.

Delhom, Joel, Manuel González. Prada et ses sources d'influence. De la philosophie à la politique, Thèse de doctorat en Études ibériques, Université de Perpignan, janvier 1996.

Delhom, Joel, "Manuel González Prada (1844-1918): del ensayo al panfleto", en Pacarina del Sur, año 3, $\mathrm{n}^{\circ} 11$, abril-junio 2012. Disponible en línea <http://www.pacarinadelsur.com/home/figuras-eideas/430-manuel-gonzalez-prada-1844-1918-del-ensayo-al-panfleto $>$.

Delhom, Joel, "Esbozo de una tipología temática y funcional de los usos de la biblia en el anarquismo hispánico", Joel Delhom y Daniel Attala (dirs.), Cuando los anarquistas citaban la Biblia. Entre mesianismo y propaganda, Madrid, Catarata, 2014, pp. 233-274.

Delhom, Joel, "Manuel González Prada et le régime de la propriété. Idées radicales et esthétique d’une sémiotique intertextuelle de propagande", en Revue Amerika - Dossier "En torno a Manuel González Prada: el pensamiento radical como fermento literario y social", $\mathrm{n}^{\circ} 17$, Université Rennes 2 , Haute Bretagne, 2018. Disponible en línea <https://journals.openedition.org/amerika/8393>.

Gómez Quiñones, Juan, Las ideas políticas de Ricardo Flores Magón. México DF, Ediciones Era, 1977.

González Prada, Manuel, Libertarias, París, Tipografía de Louis Bellenand et Fils, 1938.

González Prada, Manuel, Anarquía, Santiago de Chile, Edit. Ercilla, 1936.

González Prada, Manuel, Anarquía, Santiago de Chile, Edit. Ercilla, 1940.

González Prada, Manuel, Presbiterianas, Lima, Imprenta El Olimpo, 1909.

González Prada, Manuel, Prosa menuda, Buenos Aires, Edit. Imán, 1941.

Margarucci, Ivanna, "Manuel González Prada. Preguntas, respuestas y propuestas sobre la cuestión indígena durante un cuarto de siglo del Perú contemporáneo, 1871-1906", en Revue Amerika - Dossier "En torno a Manuel González Prada: el pensamiento radical como fermento literario y social", nº17, Université Rennes 2, Haute Bretagne, 2018. Disponible en línea $<$ https://journals.openedition.org/amerika/8377>.

Salvattecci, Hugo García, Elpensamiento de Gonzalez, Prada, Lima, Editorial Arica, 1972.

Sánchez, Luis Alberto, Don Manuel, Lima, Editorial Rosay, 1930

Sánchez, Luis Alberto, Elogio de Don Manuel González Prada, Lima, Imp. Torres Aguirre, 1922

Sánchez, Luis Alberto, Mito y realidad de González Prada, Lima, Ed. Villanueva, 1976.

Sánchez, Luis Alberto, Nuestras vidas son los ríos... Historia y leyenda de los González Prada, Lima, Universidad Nacional Mayor de San Marcos, Dirección Universitaria de Biblioteca y Publicaciones, 1977.

Sobrevilla, Manuel (comp.), Manuel González Prada. iLos jóvenes a la obra! Textos esenciales, Lima, Fondo Editorial del Congreso del Perú, 2009. 
Sobrevilla, Manuel, "Intelectuales en el Perú: literatura, sociedad y política", en Patio de Letras, Vol. II, 2004, nº1, pp. 33-44.

Sulmont, Denis, Historia del movimiento obrero peruano (1890-1977), Lima, Centro de Publicaciones Educativas, 1977.

Ward, Thomas, La anarquía inmanentista de Manuel González Prada, Lima, Universidad Ricardo Palma; Editorial Horizonte, 2001.

Ward, Thomas (ed.), "El porvenir nos debe una victoria": la insólita modernidad de Manuel González Prada, Lima, Red para el Desarrollo de las Ciencias Sociales en el Perú, 2010. 